\title{
Генерализованные эпилепсии:
} \section{современные концепции и терапевтические подходы}

В последние годы представления о генерализованной эпилепсии претерпели существенные изменения: выявлены черты фокальности при генерализованных эпилепсиях и типичные черты идиопатических генерализованных эпилепсий при фокальных эпилепсиях. Близость этих форм подтверждают и генетические исследования, когда при одном генетическом нарушении наблюдаются многообразные фокальные и генерализованные фенотипы у разных членов одной семьи. В связи с этим комиссия по терминологии и классификации Международной противоэпилептической лиги (МПЭЛ) предлагает отказаться от выделения форм эпилепсии по принципу «фокальные-генерализованные», заменив его понятием нейронной сети, вовлекающей различные локальные и общие механизмы мозга в каждом индивидуальном случае. Эти нейропатофизиологические представления объясняют причины неэффективности и иногда даже усугубляющего тяжесть заболевания влияния фармакотерапии, построенной на модели «фокальные-генерализованные припадки». Современный подход делает предпочтительным выбор препарата с широким спектром действия (помогающего при любых типах припадков и формах эпилепсии) с учетом его эффективности, скорости титрования дозы, лекарственной формы, побочных явлений и стоимости. Среди препаратов с широким спектром действия (вальпроат - ВПА, леветирацетам, ламотриджин, топирамат) в качестве первого выбора для начального лечения генерализованных эпилепсий приоритетными являются оригинальные формы ВПА с контролированным высвобождением действующего вещества - Депакин хроно и Депакин хроносфера. Рассматриваются основные фармакокинетические и фармакодинамические свойства препаратов для лечения эпилепсии и алгоритмы терапии отдельных форм генерализованной эпилепсии.

Ключевые слова: генерализованные эпилепсии, вальпроат, карбамазепин, леветирацетам, топирамат, ламотриджин.

Generalized epilepsies: current conceptions and therapeutic approaches

\section{L.R. Zenkov}

A.Ya. Kozhevnikov Clinic of Nervous Diseases, Laboratory of Clinical and Electrophysiological Studies, I.M. Sechenov First Moscow State Medical University

The concepts of generalized epilepsy have recently undergone considerable changes: the features of focality in generalized epilepsies and the typical features of idiopathic generalized epilepsies in focal epilepsies have been revealed. The closeness of these forms is also supported by genetic studies when one genetic abnormality shows diverse focal and generalized phenotypes in different members of one family. In this connection, the Commission on Classification and Terminology of the International League Against Epilepsy proposes to abandon the identification of the forms of epilepsy on the principle of focal and generalized seizures, by changing it for the notion Tneural network $y$ that involves different local and common brain mechanisms in each individual case. These neuropathophysiological concepts give an insight into why the pharmacotherapy based on a model of focal and generalized seizures is ineffective or occasionally even aggravates the disease. The current approach makes it preferential to choose a broad-spectrum drug that is effective in any types of seizures and forms of epilepsy, by taking into account its efficacy, dose titration rate, dosage form, side effects, and cost. Among broad-spectrum agents (valproate (VPA), levetiracetam, lamotrigine, topiramate), the original controlled release dosage forms of VPA (Depakine chrono and Depakine chromosphere) have a priority as first-line drugs for the initial treatment of generalized epilepsies. The paper considers the basic pharmacokinetic and pharmacodynamics properties of the drugs for the treatment of epilepsy and the algorithms of therapy for individual entities of generalized epilepsy.

Key words: generalized epilepsies, valproate, carbamazepine, levetiracetam, topiramate, lamotrigine.

Первое десятилетие XXI в. характеризовалось значительным обогащением клинической семиотики эпилептических синдромов и припадков, совершенствованием представлений о механизмах развития и конкретных клинических проявлениях эпилепсии, разработкой большого количества новых противоэпилептических препаратов (ПЭП) и выявлением новых сторон действия уже известных. Обогатились и представления о взаимоотношении структурных, нейродинамических и генетических факторов при этом заболевании. Все это заставило пересмотреть терминологию, классификацию эпилепсий и синдромов, подходы к их фармакотерапии, поскольку применявшаяся ранее парадигма выбора препаратов исходя из дихотомии «фокальные - генерализованные припадки» без учета формы эпилепсии, нейрофизиологических, генетических и других аспектов часто не только оказывается неэффективной, но и приводит к утяжелению заболевания. Систематизация новых знаний напрямую влияет на эффективность клинической практики. Цель настоящей публикации систематизировать современные представления о генерализованных эпилепсиях и на этой основе сформулировать принципы и алгоритмы их фармакотерапии. 


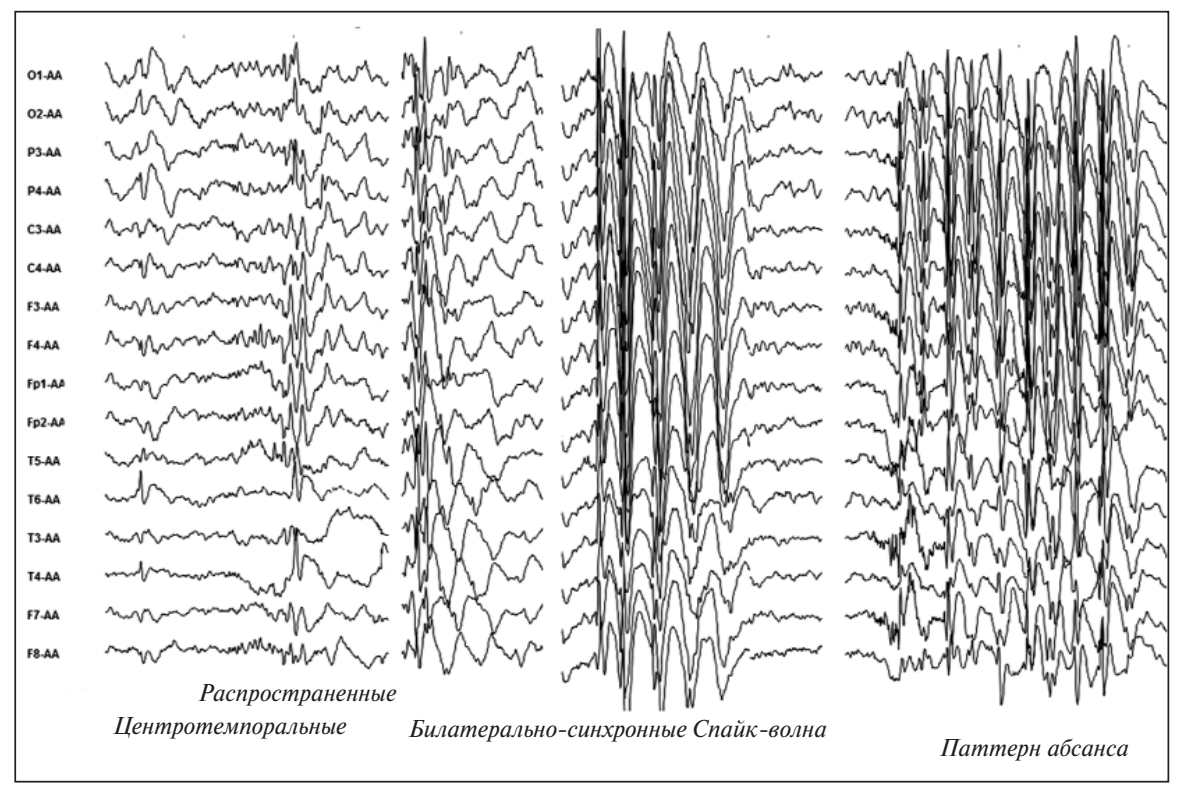

Рис. 1. ЭЭГ больной В., 6 лет. Задержкка речевого и общего развития, дефицит внимания и гиперактивность, нарушение эмоций и поведения. На последовательных фрагментах записи на протяжении 40 с видно нарастание амплитуды центротемпоральных спайков с присоединением бифронтальных острых волн, далее - полвление генерализованных билатерально-синхронных комплексов спайк-волна, серийных билатерально-синхронных комплексов спайк-волна и, наконеи, паттернов типичных абсансов, проявляющихся нарушением сознания ниях некоторых из них (синдромы Уэста, Леннокса-Гасто и др.) содержались черты и характеристики фокальных форм; 2) в отношении некоторых других форм в дальнейшем были получены данные об их генетической природе. В результате часть «симптоматических генерализованных» эпилепсий в дальнейших предложениях комиссии МПЭЛ перешла в раздел идиопатических (эпилепсия с миоклонико-атоническими припадками, эпилепсия с миоклоническими абсансами), а синдромы Уэста и Леннокса-Гасто наряду с рядом других форм - в новую рубрику: «эпилептические энцефалопатии». Таким образом, реально все первично-генерализованные формы эпилепсии оказались идиопатическими [4]. К этой подгруппе в настоящее время отнесены: доброкачественная миоклоническая эпилепсия младенчества; эпилепсия с миоклонико-атоническими припадками; эпилепсия с миоклоническими абсансами; детская и юношеская эпилепсии с абсансами; юношеская миоклоническая эпилепсия; эпилепсия, проявля-

\section{эволюция концепции}

\section{генерализованных эпилепсий}

Согласно классификации эпилепсий и эпилептических синдромов 1989 г., генерализованной называют такую эпилепсию, при которой все типы припадков являются первично-генерализованными. В свою очередь первично-генерализованными считаются припадки, «при которых первые клинические проявления указывают на начальное вовлечение обеих гемисфер; связанный с припадком начальный электроэнцефалографический паттерн также изначально двусторонний» [1, 2]. В этой классификации генерализованные эпилепсии подразделяются на идиопатические (т.е. не имеющие другой причины, кроме генетической предрасположенности), симптоматические (связанные с другим поражением мозга) и криптогенные (т. е. «предположительно симптоматические»). В течение 1999-2010 гг. рабочей группой комиссии по терминологии и классификации Международной противоэпилептической лиги (МПЭЛ) эти позиции были последовательно пересмотрены. В клиникоэлектронейрофизиологическое определение генерализованного припадка было внесено уточнение: «Генерализованный эпилептический припадок концептуализируется как возникающий в некотором пункте и быстро вовлекающий билатерально распределенные нейронные сети. Такие двусторонние сети могут включать корковые и подкорковые структуры, но необязательно затрагивают всю кору. Хотя начало индивидуальных припадков может выглядеть локализованным, локализация и латерализация не совпадают от одного припадка к другому. Генерализованные припадки могут быть асимметричными» [3]. Что касается этиологии «симптоматических генерализованных» синдромов, то тут обнаруживались внутренние противоречия: 1) в определе- ющаяся только первично-генерализованными тонико-клоническими припадками; генерализованная эпилепсия с фебрильными приступами+ и идиопатическая генерализованная эпилепсия с вариабельными фенотипами. Выделение последнего варианта связано с тем, что в значительном числе случаев при эпилепсии, первоначально отнесенной к одной из перечисленных выше генерализованных форм, по мере развития заболевания могут наблюдаться приступы, характерные для других вариантов [4, 5]. Наряду с этим накапливались факты близости фокальных и генерализованных идиопатических эпилепсий. Одним из первых на возможное происхождение абсансов из префронтальной коры указал В.В. Карлов, в дальнейшем обосновавший это положение методом компьютерной локализации источников на электроэнцефалограмме (ЭЭГ) [6]. Фокальные проявления на ЭЭГ при эпилепсиях с абсансами обнаружены также в медиальной височной, затылочной и премоторной коре $[7,8]$. Вместе с тем описаны случаи и группы пациентов с фокальными идиопатическими эпилепсиями детского возраста (затылочно-долевая, роландическая), при которых, помимо типичных фокальных припадков, наблюдались клинические и электроэнцефалографические абсансы [1, 9-14] (рис. 1). Важно отметить, что в значительном числе случаев такая эволюция (утяжеление) фокальных эпилепсий происходит под влиянием лечения некоторыми ПЭП (карбамазепин, фенитоин, ламотриджин, вигабатрин, тиагабин, фенобарбитал) [11, 12, 14-18]. Было показано, что эти препараты приводят не только к вторичной генерализации фокальных идиопатических эпилепсий и утяжелению идиопатических генерализованных эпилепсий, но и к присоединению новых типов припадков, эпилептическим статусам, когнитивным расстройствам [10, 19-28]. 
Особенно характерно наличие фокальности для юношеской миоклонической эпилепсии: фокальные клинические проявления наблюдаются у 20-46\% больных [29, 30], фокальные знаки на ЭЭГ - у 36,7-54\% [7, 29, 31, 32] (рис. 2, 3). Пониманию связи между идиопатическими фокальными и генерализованными эпилепсиями способствовали генетические и нейрофизиологические исследования у животных и человека. У крыс с генетической абсансной эпилепсией в орофациальной коре обнаружена популяция нейронов с повышенной готовностью к пароксизмальным деполяризационным сдвигам и локальным эпилептическим разрядам. Развитию абсанса у них предшествует активация этих орофациальных нейронов с появлением спайк-волновой активности, распространяющейся по кортикофугальным путям на неспецифические ядра таламуса и по каллозальным волокнам в зеркальную область противоположного полушария, в результате чего формируется корково-подкорково-корковая билатеральная система, реализующая абсанс. Фармакологическая блокада гиперактивных орофациальных нейронов приводит к невозможности возникновения абсансов, чем доказывается первично корковый генез абсансного приступа [33, 34]. Эта модель как нельзя лучше объясняет возникновение абсансов при детской роландической эпилепсии. «Центротемпоральные спайки» (орофациальная кора), входящие в официальное название этой эпилепсии (см. рис. 1) и проявляющиеся орофациальными припадками, по описанному выше механизму могут развиваться в типичные абсансы (рис. 4). Дополнительные данные о значительной близости генерализованных и фокальных эпилепсий получены в результате генетических исследований семей, в которых один мутантный ген вызывает разнообразные фенотипические проявления фокальной и генерализованной эпилепсии [32, 35-37]. Наиболее впечатляющим является описание семьи, члены которой страдали аутосомно-доминатной эпилепсией, проявлявшейся 11 фенотипами: идиопатической затылочной с ранним началом; идиопатической затылочной с поздним началом; идиопатической роландической; височно-долевой; фокальной моторной; мультифокальной; четырьмя формами генерализованной эпилепсии (юношеская миоклоническая; детская с миоклоническими абсансами; детская с абсансами; генерализованная с тонико-клоническими припадками фебрильные припадки+) и неклассифицированной формой эпилепсии [37]. При нейровизуализационных исследованиях идиопатических генерализованных эпилепсий выявлено значительное количество аномалий

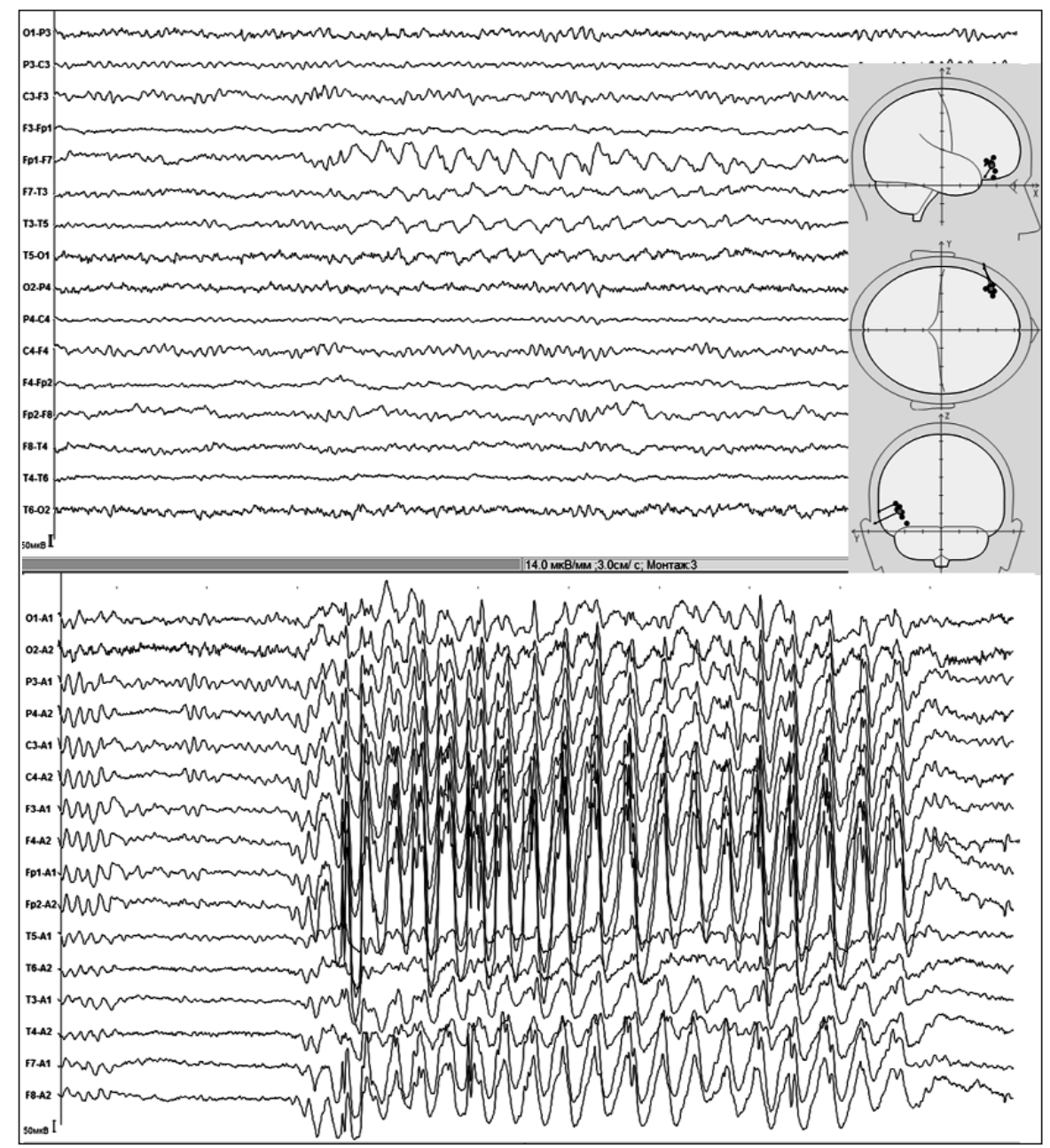

Рис. 2. ЭЭГ больной с юношеской миоклонической эпилепсией с типичными абсансами. Вверху: за 11 с до абсанса - разряд ритмичных волн 3,3 Ги с низкоамплитудным спайком в левой латерофронтальной области (трехмерная локализация источника на вкладке справа). Внизу: через 11 c-паттерн типичного абсанса с соответствующей клиникой припадка

микроструктурного развития коры [38]. Все это заставило еще раз пересмотреть вопрос о взаимоотношениях «фокальных - генерализованных» и «идиопатических - симптоматических» эпилепсий.

Таким образом, изложенные выше данные развивают и обогащают известное положение о том, что эпилепсия представляет собой проявление структурно-функциональных перестроек в мозге, затрагивающих многочисленные центры и подсистемы с ближними и дальними связями, а возникновение припадков и внеприступных психоневрологических проявлений обусловлено сложными нейронными сетями, реализующими индивидуальные варианты течения заболевания. В то же время на тех же основаниях рабочая группа МПЭЛ в итоговом документе постулировала ряд достаточно неожиданных положений, которые применительно к теме настоящего сообщения сводятся к следующему. Термины «связанные с локализацией (фокальные, парциальные)» и «генерализованные» отброшены, поскольку многие синдромы включают в себя оба типа приступов. Термин «идиопатические» предложено исключить или заменить определением «генетические», но только в случаях, 


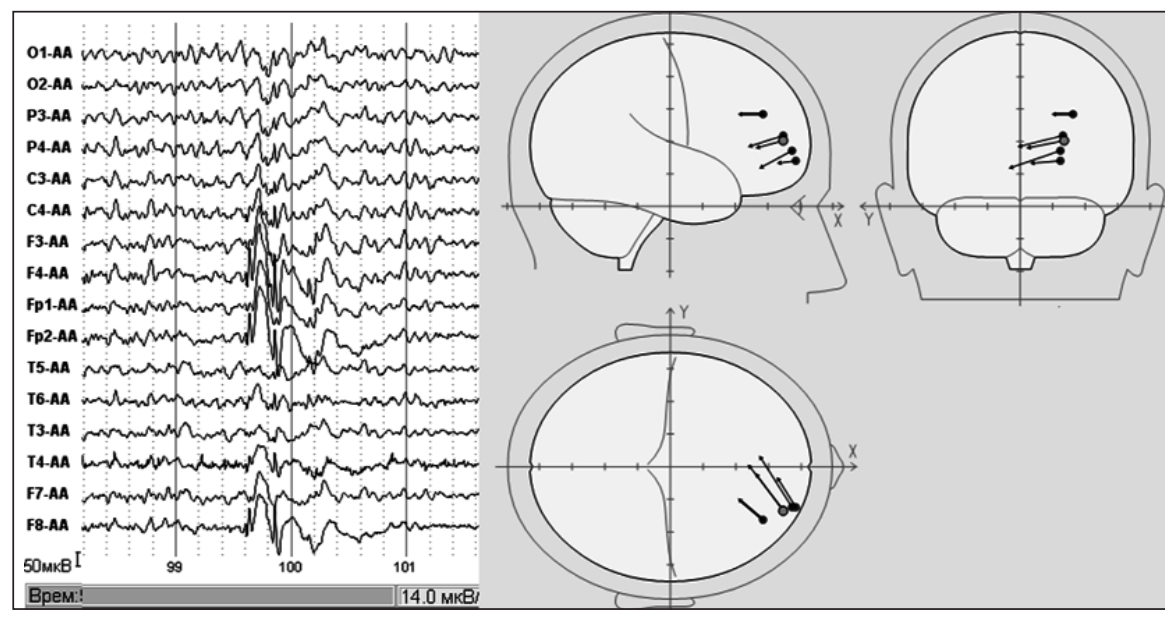

Рис. 3. ЭЭГ больного, 22 лет, с юношеской миоклонической эпилепсией. Приступы, начинающиеся с подергивания левой руки и завершающиеся генерализованным тонико-клоническим припадком с потерей сознания. Ранее лечение финлепсином утяжеляло миоклонические припадки. Лечение бензоналом уменьшило миоклонические припадки, но не влияло на генерализованные тонико-клонические. Фокус эпилептиформной активности в премоторной и фронтополярной области справа (отведения Fp2, F4, F8), соответственно началу припадка с левой руки. Справа представ-

лена трехмерная компьютерная локализация источников эпилептиформной активности. В процессе лечения бензоналом разряды мигрировали, то принимая бифронтальный характер, то перемещаясь в левую лобную область с припадками в виде двусторонних или правосторонних миоклоний в руках. Лечение Депакином хроно привело к ремиссии припадков и нормализации ЭЭГ

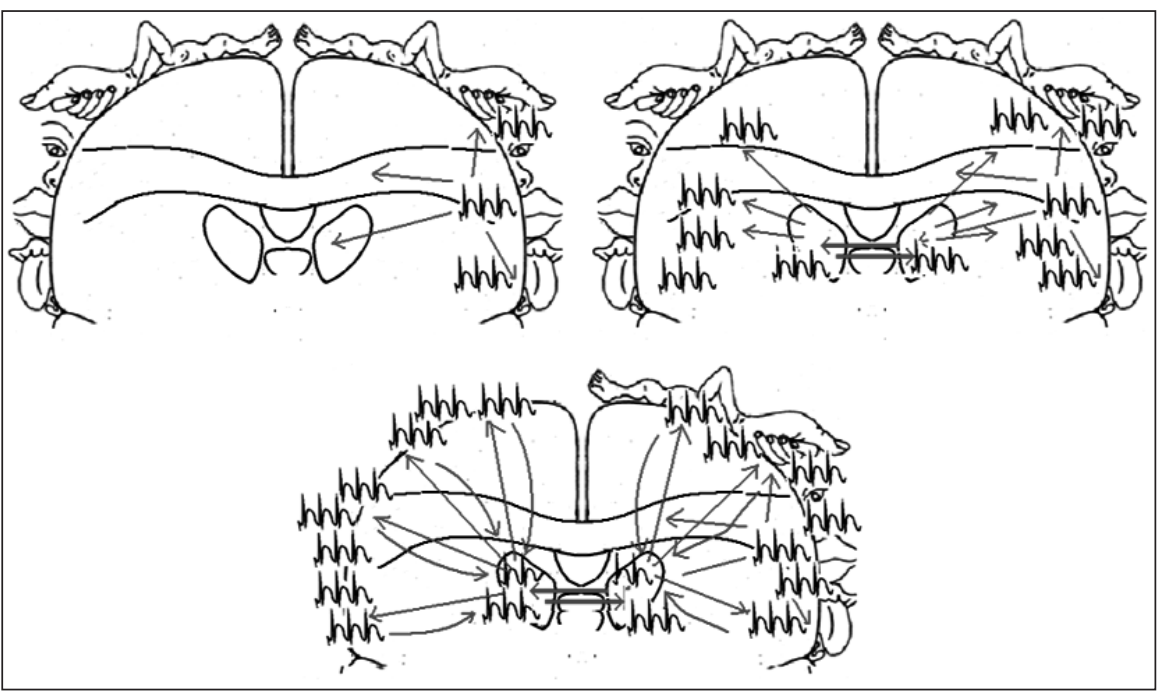

Рис. 4. Применение экспериментальной модели кортико-таламокортикального механизма генерации генерализованного паттерна спайк-волновой активности [33, 34] $\kappa$ эпилепсии с иентротемпоральными спайками с абсансами (см. рис. 1). Пароксизмальные высокочастотные разряды эпилептических нейронов (аналогичных популяции эпилептических нейронов в орофациальной коре экспериментальных животных), которые проявляются «иентротемпоральными спайками», распространяются по кортикофугальным путям на неспецифические ядра таламуса и по каллозальным волокнам в зеркальную область противоположного полушария, в результате чего формируется корково-подкорково-корковая билатеральная система, реализующая разряды абсанса

подтвержденных специальным генетическим анализом. Термин «симптоматические» рекомендовано заменить на «структурно/метаболические». В связи с изменением тер- минологии и ее конкретного содержания авторы не видят возможности привести ее в соответствие с общепринятой классификацией 1989 г. и считают необходимым отказаться от этой классификации и от какой-либо общепринятой классификации вообще. Вместо этого предлагается «гибкий подход в зависимости от конкретной ситуации» $[3,39]$. В комментариях авторы весьма жестко декларируют свою позицию: «Понятен дискомфорт от утраты старых терминов. Цепляние за них из соображений удобства и комфорта приведет к ситуации, когда клиницисты будут разговаривать на архаичном языке, в то время как ученое сообщество будет идти вперед, используя язык, более подходящий для его задач. Это создаст досадный барьер между новыми знаниями и практикой. Мы должны пройти фазу взросления, что потребует от всех определенной зрелости и терпения, а также некоторого времени. Откладывать далее ради удобства и комфорта нельзя» [39].

Эта кардинальная позиция вызвала естественную негативную реакцию у части ведущих эпилептологов, что отразилось в дискуссии на 29-м Международном конгрессе по эпилепсии в Риме (2011), который и проходил под соответствующим названием: «Вызовы в развитии нового подхода к классификации эпилепсии [2]». Прежде всего следует отметить, что принципы классификации 1989 г. органично согласуются с парадигмой клинического неврологического мышления, отражая две оси постановки диагноза: локализация и этиология. Учитывая, что в настоящее время описано не менее 100 форм эпилепсий и эпилептических синдромов, достаточно органично структурированных в классификации 1989 г., которая логично обеспечивает обзорность этого множества, отказ от общей концепции данной классификации только из-за принятия новой терминологии представляется неоправданным. Подразделение на фокальные и генерализованные эпилепсии имеет четкий терапевтический смысл, а подразделение по этиологии, кроме того, - и самостоятельную клиническую практическую ценность. Одна из задач классификации - облегчение коммуникации. Принадлежность к определенной группе предполагает, что дан- 
Доля пациентов в популяиии, получающих вальпроат, и доляпаииентов сремиссией заболевания в той же популяиии

\begin{tabular}{|c|c|c|c|}
\hline \multirow[t]{2}{*}{ Страна } & \multirow[t]{2}{*}{ Источник } & \multicolumn{2}{|c|}{ Доля пациентов, \% } \\
\hline & & получающие вальпроат & с ремиссией заболевания \\
\hline Япония & Seino M.,1997 & 57 & 90 \\
\hline Англия & Appleton R. и соавт., 1995; Sander J.W., 2002 & 43 & $65-70$ \\
\hline Россия (Казань) & Данилова и Исмагилов, 2001 & 15 & 28 \\
\hline Россия (Иркутск) & Кабаков, 2001 & 0 & 13 \\
\hline
\end{tabular}

ная единица уже обладает набором признаков, которые нет смысла перечислять. Поэтому предполагается, что число групп и число элементов внутри них ограничиваются общностью характеристик, чтобы была возможность ими эффективно оперировать. При аннулировании имеющейся классификации все множество уже известных форм станет трудно обозримым даже для опытного эпилептолога, не говоря уже о практических врачах. Теряется возможность определения места вновь обнаруживаемых форм и синдромов в контексте уже известных. Касаясь этого аспекта проблемы, J. Gomez-Alonso и P. Bellas-Lamas [40] справедливо отмечают: «Такая неопределенность не позволяет использовать цифровую или алфавитно-цифровую нумерацию, как в МКБ-10, для создания баз данных. Это осложняет общение профессионалов, исследования и отслеживание эпидемиологии в международном масштабе и негативно сказывается на прогрессе эпилептологии». Сложившаяся ситуация имеет два важных аспекта. Первый: нерешенная проблема усовершенствования старой классификации или разработки новой потребует дополнительных усилий всего неврологического сообщества на протяжении ряда лет. Второй: конкретные реалии, углубление и усложнение представлений о патогенетических, этиологических, генетических и нейрофармакологических аспектах эпилепсий требуют пересмотра практических подходов к ведению таких пациентов, формулирования новых стратегий фармакотерапии, оценки прогноза. Для этого уже сейчас необходим какой-то базис. Для дальнейшего рассмотрения проблемы лечения анализируемой группы эпилепсий мы воспользовались предложениями той же рабочей группы МПЭЛ: «Вместо этого мы предлагаем открытость мышления, непредубежденность и гибкость и полагаем, что эпилепсии (и их причины) могут плодотворно организовываться в соответствии со многими измерениями и характеристиками. Каждый может выбрать характеристики в зависимости от его нужд и задау» [39]. В соответствии с этим при изложении современных подходов к лечению перечисленных форм эпилепсии мы сочли возможным объединить их в предложенную ранее той же комиссией группу идиопатических генерализованных эпилепсий $[4,5]$. Такое объединение обусловлено существенной близостью их генетики, патогенеза, предпочтительным выбором терапии и в существенной мере прогнозом.

\section{Выбор препарата для лечения идиопатических генерализованных э п ил е п с й й}

Первоначальный выбор ПЭП определяет судьбу пациента, поскольку удача или неудача в самом начале терапии формирует его отношение к лечению. Неправильный выбор препарата влечет за собой неудачи в лечении, иногда утяжеление болезни и такую ее модификацию, при которой может оказаться неэффективным дальнейший выбор препарата. Учитывая значительное усложнение представлений о механизмах развития и проявлениях генерализованных эпилепсий, которые содержат компонент фокальности, а также возможное развитие фокальных эпилепсий по фенотипу генерализованных и роль неправильного лечения в такой эволюции, выбор препарата по принципу противопоставления «фокальный - генерализованный припадок» принципиально неправилен. Наиболее адекватным является выбор препарата в зависимости от конкретной формы электроклинического синдрома. Раздел пролегает не столько по линии «фокальные/генерализованые», сколько по линии «идиопатические/симптоматические» эпилепсии. Биологическая, патогенетическая, нейрофизиологическая, нейрохимическая, нейрофармакологическая близость фокальных и генерализованных идиопатических эпилепсий больше, чем фокальных симптоматических и фокальных идиопатических.

Таким образом, учитывая сложность диагностики и, соответственно, вероятность неправильного выбора препарата, целесообразно использовать лекарства с максимально широким спектром действия и минимальным риском утяжеления эпилепсии: вальпроат (Депакин хроно, Депакин хроносфера), леветирацетам (Кеппра), ламотриджин (Ламиктал), топирамат (Топамакс).

Рекомендации МПЭЛ по начальному лечению эпилептических припадков и синдромов завершаются заключением о невозможности выработки доказательных стандартов начальной терапии из-за отсутствия правильно организованных и проведенных рандомизированных контролируемых исследований (РКИ), посвященных лечению генерализованных эпилепсий. И, соответственно, констатируется, что окончательный выбор препарата для начального лечения эпилепсии в отсутствие доказанных преимуществ эффективности должен исходить из сравнительной оценки результатов эффективности каждого препарата, его профиля 


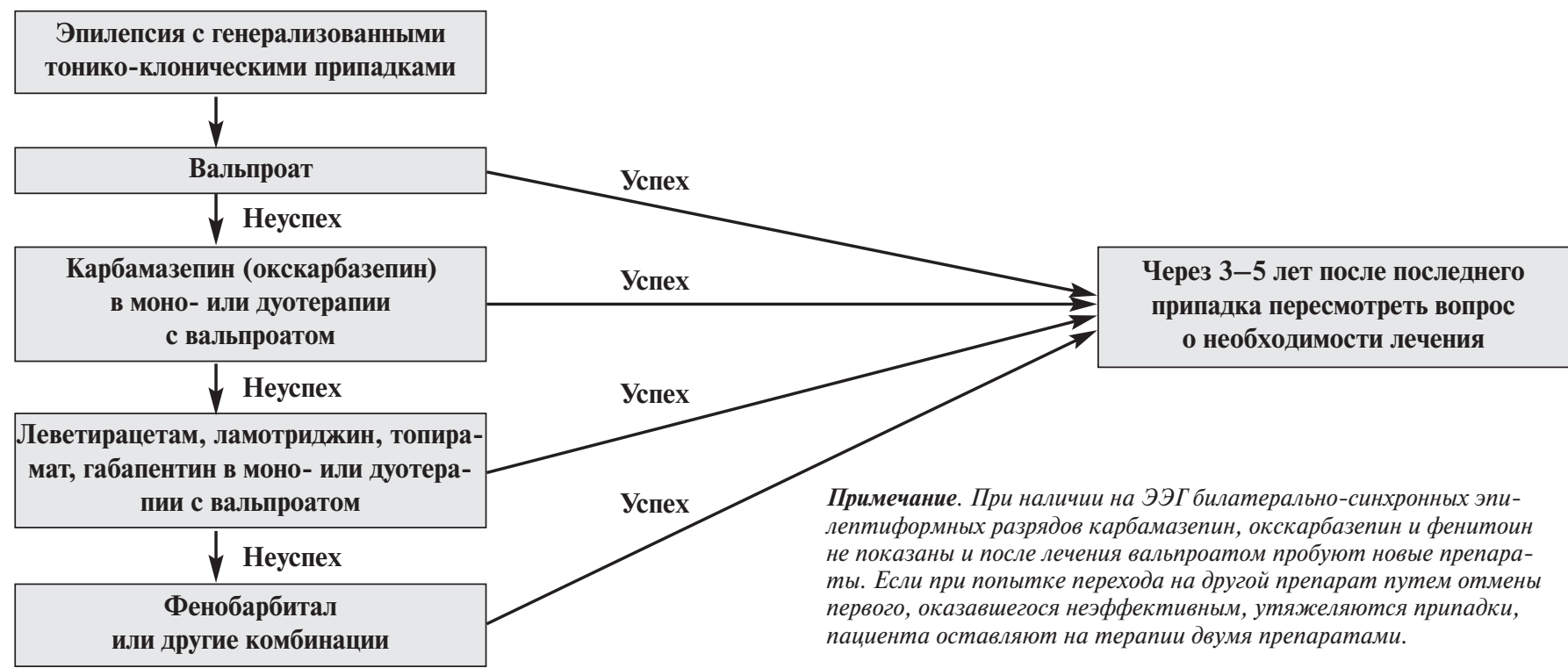

Рис. 5. Фармакотерапия идиопатической генерализованной эпилепсии с тонико-клоническими припадками

безопасности и переносимости, фармакокинетики, лекарственной формы и стоимости [41]. Руководствуясь этими рекомендациями, рассмотрим последовательность выбора одного из перечисленных выше препаратов для начальной терапии генерализованной эпилепсии. Прежде всего в наиболее адекватных клинической практике национальных рекомендациях, включая протокол ведения больных эпилепсией Минздравсоцразвития РФ, указано, что, если нет индивидуальных противопоказаний, начинать лечение эпилепсии нужно с традиционных препаратов (вальпроата или карбамазепина) [41-45]. При этом вальпроат (Депакин хроно, Депакин хроносфера) назван «оплотом современного лечения эпилепсии» [46], что доказано более чем 40-летней мировой врачебной практикой. Вальпроат - наиболее широко применяемый ПЭП, на долю которого, например, в Японии приходится до 60\%, а в среднем в мире - около $30 \%$ всех назначений ПЭП [42, 43, 46-49]. Любопытно, как со- относится эффективность лечения в разных популяциях с процентом пациентов, получающих вальпроат, по данным разных авторов и нашим данным (см. таблицу).

Коэффициент корреляции (r) между данными, представленными в таблице, составляет $0,98(\mathrm{p}=0,004)$, что говорит о теснейшей прямой взаимосвязи успешности лечения и применения вальпроата. Положительные результаты терапии вальпроатом определяются его высокой эффективностью (70-90\% ремиссии при монотерапии), широтой терапевтического действия (Депакин эффективен при всех формах эпилепсии и всех типах припадков), хорошей переносимостью, возможностью быстрого наращивания дозы, благоприятным взаимодействием с другими препаратами [7, 42, 43, 46-48, 50, 51]. Пролонгированные формы (Депакин хроно, Депакин хроносфера) обеспечивают устойчивую терапевтическую концентрацию препарата в крови, минимальный риск побочных эффектов и существенно уменьшают зависимость пациента от

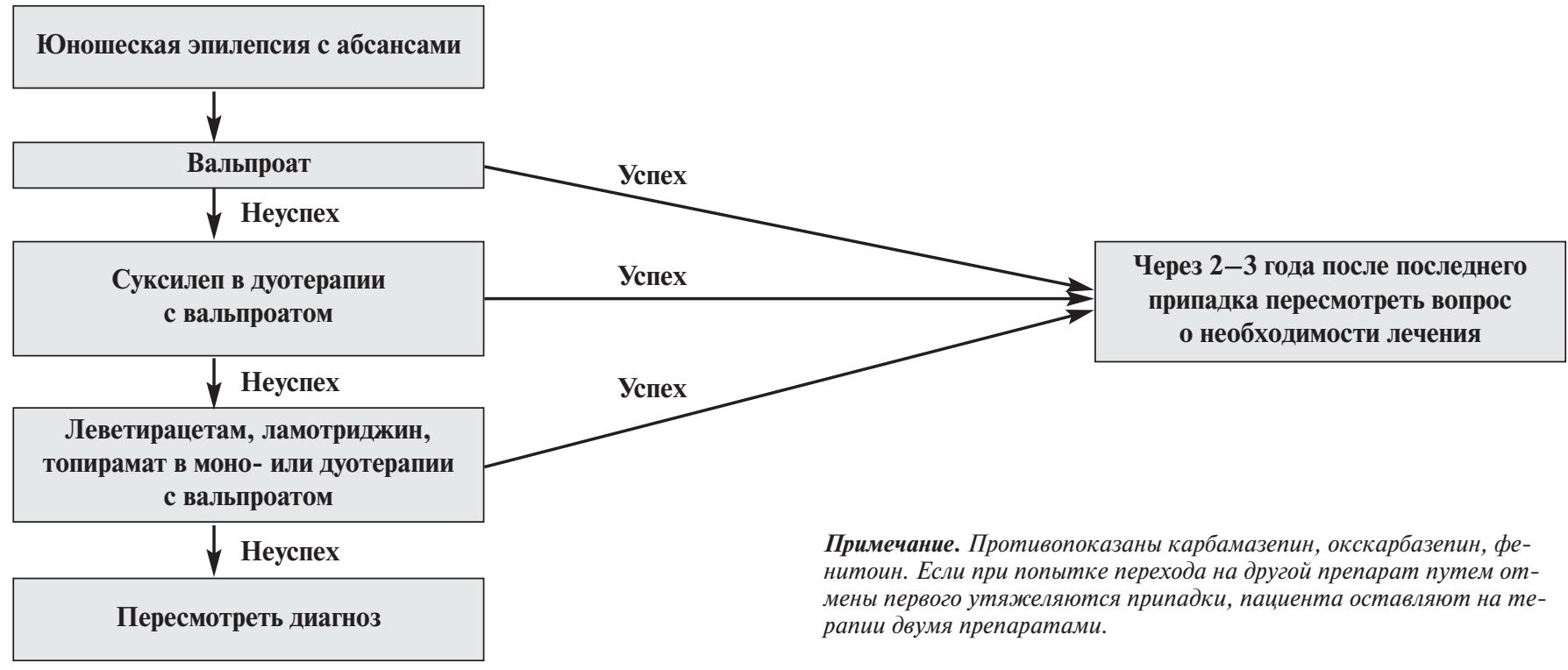

Рис. 6. Фармакотерапия идиопатической генерализованной эпилепсии с абсансами юношеского возраста 
лекарства, поскольку суточную дозу можно поделить на два приема или даже принять один раз вечером [7, 49, 52]. Дополнительными преимуществами вальпроата являются отсутствие (или редкость и предсказуемость) непереносимости, утяжеления припадков. Вальпроат, эффективно подавляя эпилептиформную активность на ЭЭГ, а следовательно, и эпилептические разряды, высвобождает нейроны для осуществления нормальной функциональной активности, что определяет ее нормализующее психокогнитивное действие [15, 51].

Вальпроат обладает нейропротективными и противоэпилептическими свойствами. Вследствие подавления разрядной интериктальной активности препарат предотвращает киндлинг, патологический аксональный спрутинг и эпилептический нейрогенез. Блокируя $\mathrm{Ca}^{2+}-$ каналы, он препятствует эксайтотоксической гибели нейронов, нормализует метаболизм и информационную активность нервных клеток и глии, регулирует рецепторы, нейротрансмиттеры, вторичные мессенджеры, генно-транскрипционные факторы, сигнальные протеины, киназы, нейротрофические факторы и апоптоз. Вальпроат обеспечивает выживание нейронов через факторы роста и массивное увеличение уровня нейропротективного протеина bcl-2. Все это способствует предотвращению прогрессирования эпилептического процесса и реальному излечению [47].

Депакин особенно эффективен при детской эпилепсии и эпилептической энцефалопатии, в основе которых лежит незрелость нейрональных систем. Под влиянием вальпроата в стволовых клетках (нейробластах) наблюдаются активный рост дендритов и аксонов и образование из них хорошо организованной нейронной сети, т. е. созревание корковых структур, которое идет преимущественно по линии ГАМК-ергических тормозных нейронов. Это объясняет эмпирически сложившийся первый выбор вальпроата при эпилептической энцефалопатии и фокальных идиопатических эпилепсиях у детей [7, 44, 45, 47, 48, 51].

Причины выбора Депакина в качестве первого препарата в лечении генерализованной эпилепсии:

- подавляет все типы эпилептических припадков при всех формах эпилепсии;

- подавляет интериктальную эпилептическую активность в мозге и препятствует киндлингу и связанному с ним прогрессированию и поддержанию эпилептического процесса;

• обеспечивает нейропротекцию, сдерживает развитие эпилептической энцефалопатии;

- способствует созреванию мозга и тем самым препятствует развитию идиопатических эпилепсий и тяжелой эпилептической энцефалопатии у детей;

- приводит к возможному излечению эпилепсии.

В соответствии с этим в рекомендациях МПЭЛ вальпроam назван препаратом первого выбора для лечения генерализованных тонико-клонических припадков у детей и взрослых [41]. При абсансах препаратами выбора признаны: вальпроат, этосуксимид и ламотриджин. Однако последние два препарата уступают вальпроату по скорости достижения терапевтического эффекта, к тому же вальпроат характеризуются минимумом противопоказаний и побочных эффектов, так что приоритет при абсансах остается за Депакином хроно и Депакином хроносфера. Не рекомендуется использовать из-за возможности утяжеления заболевания карбамазепин, фенитоин, фенобарбитал, тиагабин, вигабатрин и окскарбазепин. В независимом мультицентровом РКИ SANAD (Standard And New Antiepileptic Drugs) показано, что при первично-генерализованных припадках и неустановленном типе припадков переносимость вальпроата была значительно лучше, чем топирамата, а эффективность значительно выше, чем ламотриджина, поэтому вальпроат должен остаться препаратом первого выбора при генерализованной и неклассифицированной эпилепсии [53]. Предложение рабочей группы МПЭЛ о прекращении действия классификации эпилепсий 1989 г. автоматически делает все эпилепсии неклассифицированными, а Депакин - препаратом первого выбора при любых эпилепсиях.

Поскольку при одной из наиболее распространенных форм заболевания - юношеской миоклонической эпилепсии - припадки нередко носят локальный характер, чему соответствует и латерализованная эпилептиформная активность на ЭЭГ (см. рис. 3), такие пациенты из-за ошибочного диагноза в среднем 6 лет безуспешно или с ухудшением лечатся карбамазепином, окскарбазепином или фенитоином. При юношеской миоклонической эпилепсии эти препараты в 60-70\% случаев приводят к утяжелению состояния с присоединением генерализованных тонико-клонических приступов, абсансов и статусов $[1,17,48]$, а у остальных больных не достигается улучшения [15, 16, 45, 50].

Высоким потенциалом утяжеления течения эпилепсии обладают и другие ПЭП, включая ламотриджин, фенитоин, окскарбазепин, фенобарбитал, топирамат, леветирацетам, бензодиазепины, вигабатрин. В этом отношении особое место занимает вальпроат. В метаанализах, представленных в литературе, не зарегистрировано случаев утяжеления эпилепсии под влиянием вальпроата. Единичные наблюдения утяжеления припадков при лечении вальпроатом объясняются передозировкой, предшествующей энцефалопатией, нарушением обмена, гепатопатией [1, 16, 54].

Помимо непосредственного влияния на частоту и тяжесть припадков, при выборе препарата необходимо учитывать его побочные эффекты. Так, лечение карбамазепином в эффективных дозах (кроме риска утяжеления состояния вследствие неправильного выбора препарата) нередко сопровождается осложнениями со стороны ЦНС, что приводит к отказу от его применения [15]. Часто встречающиеся побочные эффекты со стороны ЦНС - главная проблема при начальном лечении топираматом. Поэтому рекомендуется медленное титрование дозы, что ограничивает его использование при тяжелых и частых припадках. Публикации о снижении когнитивных функций при долгосрочном лечении топираматом появляются с пугающей частотой. Из всех ПЭП топирамат обладает наибольшим потенциалом развития когнитивных дисфункций, вызывая стойкое ухудшение семантической вербальной беглости, вербального обучения, рабочей памяти и зрительно-моторных навыков. Он ухудшает лобные функции, когнитивную скорость и кратковременную память. Эти долгосрочные негативные эффекты наблюдаются даже при приеме препарата в малых дозах (50-100 мг/сут). Топирамат оказывает значительное негативное влияние на когнитивные и поведенческие функции даже у детей и подростков с умственной отсталостью [56-67]. Топирамат вызывает снижение сексуальных функций $[18,68]$. В совокупности с рядом соматических негативных эффектов указанные осложнения приводят к тому, что на 3-м году лечения топирамат продолжает 
принимать только около трети пациентов [69]. Памятуя, что при большинстве эпилепсий речь идет о долгосрочном (часто пожизненном) лечении, начальный выбор препарата, от которого 2/3 пациентов на 3-м году откажутся, нецелесообразен. В монографии, отражающей позицию экспертов МПЭЛ, констатировано, что «топирамат - наихудший из новых ПЭП в отношении побочных реакций, которые часты, многообразны и иногда тяжелы и потенциально фатальны» $[1,58]$.

В лечении эпилепсий с абсансами эффективен ламотриджин [41, 53, 69]. Фактором, ограничивающим его применение, является сыпь (у 5-15\% пациентов), требующая в соответствии с предостережением фирмы-производителя немедленной его отмены из-за риска тяжелых осложнений в виде синдрома Стивенса-Джонсона и Лайелла. Для минимизации этого риска необходимо очень медленное титрование дозы, поэтому достижение эффективной дозы откладывается на недели и месяцы, что делает препарат неприемлемым в качестве начальной терапии при частых и тяжелых припадках.

Таким образом, сравнение препаратов по показателям эффективность/безопасность показывает преимущество вальпроата (Депакин хроно, Депакин хроносфера) в лечении генерализованной эпилепсии. Вальпроат обычно не вызывает осложнений со стороны ЦНС. Наблюдающийся в части случаев тремор (характерный и при использовании других препаратов) возникает при приеме максимальных доз и уменьшается при снижении дозы. Тремор обычно появляется в условиях психологического стресса и поддается терапии бета-адреноблокаторами. Вальпроат может вызывать увеличение массы тела, что, однако, можно контролировать соблюдением диеты и достаточной физической активностью. У пожилых пациентов этот побочный эффект вообще отсутствует [70]. Значительно лучшая переносимость вальпроата и его высокая эффективность обеспечивают высокий уровень удержания на препарате: 60-80\% пациентов продолжают принимать его 3 года и более [49, 71-75]. Наконец, важным компонентом выбора препарата является стоимость лечения - у вальпроата она наиболее низкая. Ocобое внимание требуется при назначении вальпроата женщинам, в частности беременным. У вальпроата больший, чем у других препаратов, риск тератогенных осложнений. Однако существенные различия выявляются только при дозах >1000 мг/сут. Экскреция вальпроата с молоком матери не превышает $3 \%$ и не имеет клинического значения [42]. Надежды, возлагавшиеся на безопасность других препаратов в отношении тератогенеза, не получили доказательного подтверждения. По последним данным, при лечении топираматом частота больших врожденных мальформаций составляет 9\%, оральные расщепления встречаются в 11 раз чаще, чем в среднем в популяции (регистр беременностей Великобритании [76]). У 684 младенцев, подвергавшихся внутриутробному воздействию ламотриджина, в 10,4 раза выше риск орального расщепления, чем у не подвергавшихся такому воздействию (Североамериканский регистр беременностей [77]).

Таким образом, при решении вопроса о лечении эпилепсии следует учитывать и сравнительно оценивать следующие факторы [41, 48]:

- форму эпилепсии и чувствительность больного к данному препарату;

- скорость достижения контроля припадков, зависящую от скорости титрования дозы;
• вероятность утяжеления припадков, ухудшения когнитивных функций;

- неблагоприятные побочные эффекты;

- стоимость лечения;

- длительность поддержания лечебного эффекта (удержания на препарате), определяемую сохранением терапевтической активности и непереносимыми побочными эффектами.

По всем этим позициям вальпроат (Депакин хроно, Депакин хроносфера) обладает несомненным преимуществом, что определяет целесообразность начала лечения любых форм эпилепсии именно с этого препарата. При правильно подобранной дозе вальпроат обеспечивает ремиссию в 60-90\% случаев. Важным достоинством препарата является поддержание стабильной терапевтической концентрации в крови, что достигается при применении форм с контролируемым высвобождением действующего вещества. Последняя разработка - Депакин хроносфера, представляющая собой микрогранулы без запаха и вкуса, которые можно принимать с пищей, обеспечивает беспрецедентные возможности лечения пациентов, которые по каким-либо причинам не могут принимать крупные таблетки. У недостаточно «контролируемого» пациента любого возраста незаметное добавление препарата в пищу обеспечивает регулярное лечение [78, 79].

\section{Алгоритмы фармакологическоголечения основных 中ормгенерализованых \\ эпилеп сий и эпилептиче ских синдромов}

Если нет противопоказаний, начинать лечение любых генерализованных форм эпилепсии следует с монотерапии вальпроатом с контролированным высвобождением (Депакин хроно, Депакин хроносфера) и доводить дозу до эффективной. Если при использовании максимально приемлемой дозы эффект не достигнут, добавляют другой препарат, соответствующий форме эпилепсии, и в случае успеха делают попытку перейти на монотерапию этим препаратом. Если не удается полностью отменить первый препарат, пациента оставляют на терапии двумя лекарственными средствами. При неэффективности традиционных препаратов добавляют или постепенно переходят на один из новых препаратов (леветирацетам, ламотриджин, топирамат, окскарбазепин) по тем же правилам. Рекомендуется использовать одновременно не более двух ПЭП. Как исключение добавляют, желательно кратковременно, третий ПЭП.

Выбор препарата зависит от точности диагноза: 1) диагноз «эпилепсия с генерализованными припадками», но не удалось уточнить форму; 2) установлена форма эпилепсии, относящаяся к одной из основных подгрупп классификации и терминологии.

\section{Лечение эпилепсии сгенерализованными припадками при неуточненной форме}

Если точно не установлена форма эпилепсии, лечение начинают с препарата с наиболее широким спектром действия - Депакина хроно, Депакина хроносфера. При успехе и медикаментозной ремиссии в течение 2-5 лет может быть поставлен вопрос о постепенной отмене препарата. При неэффективности вальпроата уточняют форму эпилепсии и подбирают более специфичный препарат. 


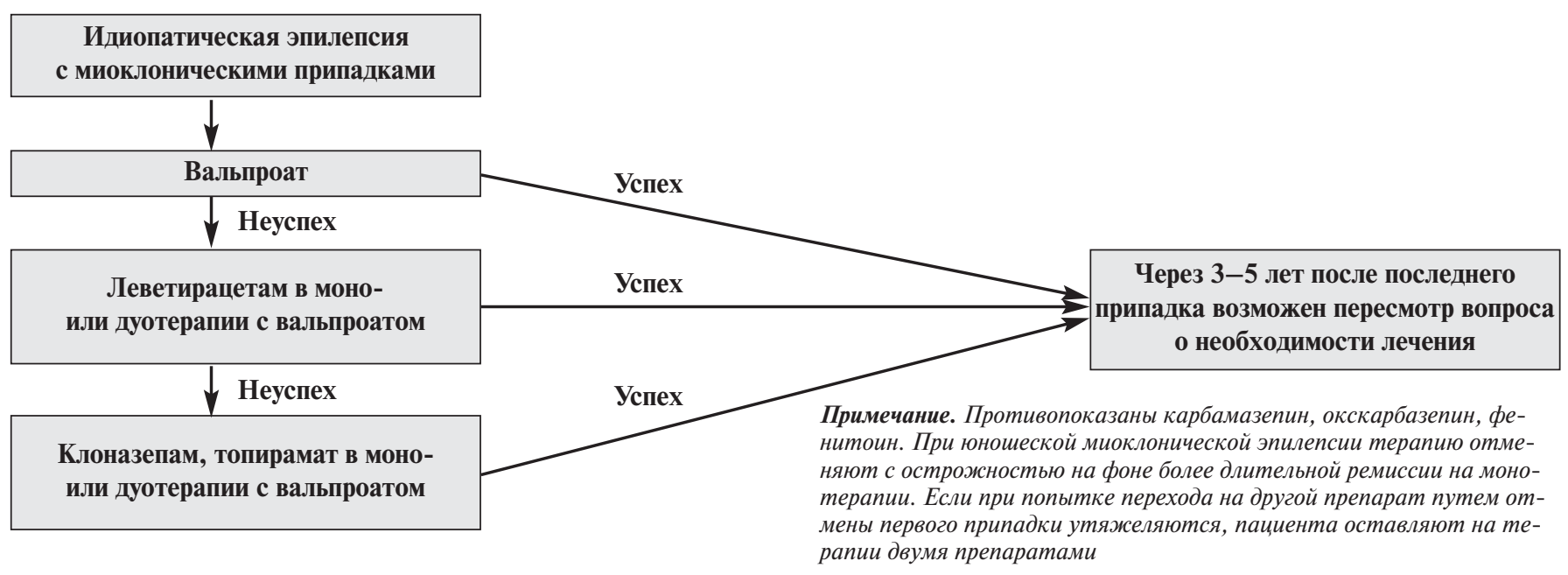

Рис. 7. Фармакотерапия идиопатических генерализованных эпилепсий с миоклоническими припадками

\section{Лечение идиопатической эпилепсии с генерализованными} тонико-клоническими припадками

Препарат первого выбора - вальпроат. В случае неудачи при отсутствии билатерально-синхронных эпилептиформных разрядов на ЭЭГ выбирают карбамазепин или окскарбазепин. Выбор одного из этих двух препаратов объясняется тем, что при неэффективности вальпроата может оказаться, что на самом деле речь идет о вторично-генерализованной эпилепсии. При неэффективности лечения карбамазепином или окскарбазепином пробуют новые препараты: леветирацетам, ламотриджин, топирамат в приведенном порядке. Эти же препараты, минуя карбамазепин и окскарбазепин, используют при наличии на ЭЭГ билатерально-синхронных эпилептиформных разрядов в случае неэффективности вальпроата. При успешном лечении дополнительным препаратом делают попытку перехода на монотерапию. Если припадки утяжеляются при уменьшении дозы первого препарата, пациента оставляют на терапии двумя лекарственными средствами. При неэффективности указанных выше препаратов пробуют фенобарбитал и другие комбинации (рис. 5).

\section{Лечение идиопатической эпилепсии с абсансами}

При лечении абсансной эпилепсии детского возраста препараты первого выбора - вальпроат, второго - этосуксемид, ламотриджин, леветирацетам, топирамат. Противопоказаны карбамазепин, окскарбазепин, фенитоин, фенобарбитал. Лечение юношеской эпилепсии с абсансами проводят теми же препаратами, но этосуксемид не следует использовать для монотерапии, так как он неэффективен при генерализованных тонико-клонических припадках (рис. 6).

Лечение детских и юношеских идиопатических генерализованных эпилепсий с миоклоническими припадками (юношеская миоклоническая эпилепсия, эпилепсия с миоклонико-астатическими припадками, эпилепсия с миоклоническими абсансами)

Препарат первого выбора - вальпроат. При неуспешности терапии вальпроатом используют леветирацетам. Препараты дальнейшего выбора - клоназепам, топирамат, фенобарбитал, этосуксемид, ламотриджин. При отсутствии абсансов нецелесообразно пробовать этосуксемид. Ламотриджин иногда может утяжелять миоклонии. Противопоказаны карбамазепин, фенитоин, окскарбазепин (рис. 7).

\section{Л И Т E P A T V P A}

1. Panayiotopoulous C.P. A clinical guide to epileptic syndromes and their treatment. Revised second edition based on the ILAE classification and practice parameter guidelines. Springer, 2010;620 p.

2. $29^{\text {th }}$ International Epilepsy Congress. $28^{\text {th }}$ August $-1^{\text {st }}$ September 2011. Rome. Italy. Plenary Session. Challenges in developing a new approach for classification in epilepsy. Chairs: A. Berg \& Capivola.

3. Berg A.T., Berkovic S.F., Brodie M.J. et al. Revised terminology and concepts for organization of seizures and epilepsies: Report of the ILAE Commission on Classification and Terminology, 2005-2009. Epilepsia 2011;52(6):1058-62. 4. Engel J.Jr. A proposed diagnostic scheme for people with epileptic seizures and with epilepsy: report of the ILAE Task Force on Classification and Terminology. Epilepsia 2001;42:796-803.

5. Воронкова К.В., Холин А.А.,

Пылаева О.А. и др. Идиопатические генерализованные эпилепсии: современный взгляд.

Фокальные черты идиопатических генерализо- ванных эпилепсий. Medi.ru. Эпилепсия 2010;1:3-8.

6. Карлов В.А., Гнездицкий В.В. Абсансная эпилепсия у детей и взрослых. М.: Прессервис, 2005;63 c.

7. Зенков Л.Р. Клиническая эпилептология. Рук-во для врачей. Изд. 2-е, испр. и доп. М.: МИА, 2010;408 c.

8. Caraballo R.H., Fontana E., Darra F. et al. Childhood absence epilepsy and electroencephalographic focal abnormalities with or without clinical manifestations. Seizure 2008;17(7):617-24.

9. Cerminara C., Montanaro M.L., Curatolo P. et al. Lamotrigine-induced seizure aggravation and negative myoclonus in idiopathic rolandic epilepsy. Neurology 2004;63:373-5.

10. Gelisse P., Genton P., Bureau M. et al. Are there generalised spike waves and typical absences in benign rolandic epilepsy? Brain Dev 1999;21(6):390-6.

11. Hamano S., Mochizuki M., Morikawa T. Phenobarbital-induced atypical absence seizure in benign childhood epilepsy with centrotemporal spikes. Seizure 2002;11(3):201-14.

12. Kramer U. Atypical Presentations of Benign Childhood Epilepsy With Centrotemporal Spikes: A

Review. J Child Neurol 2008;23:785-90.

13. Montenegro M.A., Guerreiro M.M.

Coexistence of Childhood Absence and Rolandic

Epilepsy. J Child Neurol 2006;21:535-6.

14. Dimova P.S., Daskalov D.S. Coincidence of

Rolandic and Absence Features: Rare, but not

Impossible. J Child Neurol 2002;17:838-46.

15. Зенков Л.Р. Осложнения

противоэпилептической фармакотерапии.

РМЖ 2004;6:9-12.

16. Зенков Л.Р. Утяжеление эпилепсии

вследствие противосудорожной

фармакотерапии. Неврол журн

2007;12(3):8-13.

17. Gelisse P., Genton P., Kuate C. et al. Worsening of seizures by oxcarbazepine in juvenile idiopathic generalized epilepsies. Epilepsia 2004;45:1282-6.

18. Lawrence N.C., Broner S.W., Lay C.L.

Reversible anorgasmia with topiramate therapy for 
migraine. Neurology 2005;65:1333-4. 19. Bauer J. Seizure-inducing effects of antiepileptic drugs: a review. Review. Acta Neurol Scand 1996;94:367- 77

20. Biraben A., Allain H., Scarabin J.M. et al. Exacerbation of juvenile myoclonic epilepsy with lamotrigine. Neurology 2000;55:1758.

21. Guerrini R., Belmonte A., Genton P.

Antiepileptic drug-induced worsening of seizures in children. Epilepsia 1998;39

(Suppl. 3):S2-S10.

22. Osorio I., Reed R.C., Peltzer J.N. Refractory idiopathic absence status epilepticus: a probable paradoxical effect of phenytoin and carbamazepine. Epilepsia 2000;41:887-94. 23. Parker A.P., Agathonikou A., Robinson R.O. et al. Inappropriate use of carbamazepine and vigabatrin in typical absence seizures. Dev Med Child Neurol 1998:40:517-9.

24. Perucca E., Gram L., Avanzini G. et al. Antiepileptic drugs as a cause of worsening seizures. Review. Epilepsia 1998;39:5-17.

25. Sazgar M., Bourgeois B.F. Aggravation of epilepsy by antiepileptic drugs. Review. Pediatr Neurol 2005;33:227-34.

26. Shields W.D., Saslow E. Myoclonic, atonic and absence seizures following institution of carbamazepine therapy in children. Neurology 1983;33:1487-9.

27. Trinka E., Dilitz E., Unterberger I. et al. Non convulsive status epilepticus after replacement of valproate with lamotrigine. J Neurol

2002;249:1417-22.

28. Yang M.T., Lee W.T., Chu L.W. et al. Antiepileptic drugs-induced de novo absence seizures. Brain Dev 2003;25:51-6.

29. Jayalakshmi S.S., Srinivasa Rao B., Sailaja S. Focal clinical and electroencephalographic features in patients with juvenile myoclonic epilepsy. Acta Neurol Scand 2010;122(2):115-23.

30. Usui N., Kotagal P., Matsumoto R. et al. Focal semiologic and electroencephalographic features in patients with juvenile myoclonic epilepsy. Epilepsia 2005;46:1668-76.

31. Aliberti V.,. Grunewald R.A, Panayiotopoulos C.P. et al. Focal electroencephalographic abnormalities in juvenile myoclonic epilepsy. Epilepsia 1994:35(2):297-301.

32. Taylor I., Marini C., Johnson M.R. et al. Juvenile myoclonic epilepsy and idiopathic photosensitive occipital lobe epilepsy: is there overlap? Brain 2004; 127:1878-86.

33. Polack P.-O., Guillemain I., Hu E. et al. Deep Layer Somatosensory Cortical Neurons Initiate Spike-and-Wave Discharges in a Genetic Model of Absence Seizures. J Neurosci 2007;27:6590-9. 34. Polack P.-O., Mahon S., Chavez M. et al. Inactivation of the Somatosensory Cortex Prevents Paroxysmal Oscillations in Cortical and Related Thalamic Neurons in a Genetic Model of Absence Epilepsy. Cereb Cortex 2009;19:2078-91.

35. Berkovic S.F., Scheffer I.E. Genetics of the epilepsies. Epilepsia 2001;42(Suppl. 5):16-23. 36. Mullen S.A., Suls A., De Jonghe P. et al. Absence epilepsies with widely variable onset are a key feature of familial GLUT1 deficiency. Neurology 2010:75:432-40.

37. Taylor I., Berkovic S.F., Kivity S. et al. Benign occipital epilepsies of childhood: clinical features and genetics. Brain 2008;131:2287-94.

38. Woermann F.G., Sisodiya S.M., Free S.L. Quantitative MRI in patients with idiopathic generalized epilepsy. Evidence of widespread cerebral structural changes. Brain 1998;121:1661-7. 39. Berg A.T., Scheffer I.E. New concepts in classification of the epilepsies: Entering the $21^{\text {st }}$ century. Epilepsia 2011;52(6):1058-62.

40. Gomez-Alonso J., Bellas-Lamas P. The new International League Against Epilepsy (ILAE) classification of epilepsies: a step in the wrong direction? Rev Neurol 2011;52(9):541-7.

41. Glauser T., Ben-Menachem E., Bourgeois B. et al. ILAE treatment guidelines: evidence-based analysis of antiepileptic drug efficacy and effectiveness as initial monotherapy for epileptic seizures and syndromes. Epilepsia 2006;47:1094-120. 42. Карлов В.А. Эпилепсия у детей и взрослых, женщин и мужчин. М.: Медицина, 2010;717 с. 43. Стандарты по лечению эпилепсии. Минздравсоцразвития РФ, приказ № 174 от 28.02.2005 г.

44. Wheless J.W. Managing Severe Epilepsy Syndromes of Early Childhood. J Child Neurol $2009 ; 24: 24 \mathrm{~S}-32 \mathrm{~S}$

45. Wheless J.W., Clarke D.F., Arzimanoglou A. et al. Treatment of pediatric epilepsy: European expert opinion, 2007. Epileptic Disord 2007;9:353-412.

46. Guerrini R. Valproate as a mainstay of therapy for pediatric epilepsy.

Paediatr Drugs 2006;8:113 - 29.

47. Зенков Л.Р. Место вальпроатов (Депакин) в фармакотерапии эпилепсии XXI века. РМЖ 2009; 17(11):726-33.

48. Зенков Л.Р. Современное лечение эпилепсии. Рук-во для врачей. ТОО «СанофиАвентис Казахстан», 2010.

49. Jedrzejczak J., Kuncikova M., Magureanu S. et al. An observational study of first-line valproate monotherapy in focal epilepsy. Eur J Neurol 2008; 15:66-72.

50. Зенков Л.Р. Клиническое значение изменений электроэнцефалограммы при лечении эпилепсии вальпроатом (Депакин хроно). Журн невропатол и психиатр 2002;102:20-6.

51.Зенков Л.Р. Непароксизмальные эпилептические расстройства. Рук-во для врачей. М.: МЕДпресс-информ, 2007;280 с. 52. Genton P. Progress in pharmaceutical development presentation with improved pharmacokinetics: a new formulation for valproate. Acta Neurol Scand 2005; 182:26-32.

53. Marson A.G., Al-Kharusi Asya M.

Alwaidh M. et al. The SANAD study of eff ectiveness of valproate, lamotrigine, or topiramate for generalised and unclassifi able epilepsy: an unblinded randomised controlled trial. Lancet 2007;369:1016-26.

54. Hirsch E., Genton P. Antiepileptic druginduced pharmacodynamic aggravation of seizures: does valproate have a lower potential?

CNS Drugs 2003; 17:633-40.

55. Arvio M., Sillanpaa M. Topiramate in longterm treatment of epilepsy in the intellectually dis abled. J Intellect Disabil Res 2005;49(3):183-9. 56. Baeta E., Santana I., Castro G. et al. Cognitive effects of therapy with topiramate in patients with refractory partial epilepsy. Rev Neurol 2002;34(8):737-41

57. Blum D., Meador K., Biton V, et al. Cognitive effects of lamotrigine compared with topiramate in patients with epilepsy. Neurology 2006;67:400-6. 58. Bourgeois B.F.D. Determining the Effects of Antiepileptic Drugs on Cognitive Function in Pediatric Patients With Epilepsy. J Child Neurol 2004:19:S15-S24.

59. Coppola G., Verrotti A., Resicato G. et al Topiramate in children and adolescents with epilepsy and mental retardation: a prospective study on behavior and cognitive effects. Epilepsy Behav 2008;12(2):253-6.

60. Gomer B., Wagner K., Frings L. et al. The influence of antiepileptic drugs on cognition: a comparison of levetiracetam with topiramate. Epilepsy Behav 2007;103:486-94.

61. Lee H.W., Jung D.K., Suh C.K. et al. Cognitive effects of low-dose topiramate monotherapy in epilepsy patients: A 1-year follow-up. Epilepsy Behav 2006;8(4):736-41.

62. Martin R., Kuzniecky R., Ho S. et al Cognitive effects of topiramate, gabapentin, and lamotrigine in healthy young adults. Neurology 1999;52:321.

63. Meador K.J. Cognitive Effects of Levetiracetam versus Topiramate.

Epilepsy Curr 2008;8(3):64-5.

64. Marco M., Trimble M.R., Thompson P. et al

Topiramate and word-finding difficulties in patients with epilepsy. Neurology 2003; 60:11047.

65. Rorsman I., Kallen K. Recovery of cognitive and emotional functioning following withdrawal of topiramate maintenance therapy. Seizure

2001:10(8):592-5.

66. Shechter T., Shorer Z., Kramer U. et al. Adverse reactions of Topiramate and Lamotrigine in children. Pharmacoepidemiol Drug Saf 2005;14(3):187-92

67. Thompson P.J., Baxendale S.A.

Duncan J.S. et al. Effects of topiramate on cognitive function. J Neurol Neurosurg Psychiatr 2000;69:636-41.

68. Lasaosa S.S., Fernandez L.G., del Val L.J. Anorgasmia due to topiramate. Neurologia 2008;23(8):541-2.

69. Lhatoo S.D., Wong I.C., Polizzi G. et al. Longterm retention rates of lamotrigine, gabapentin, and topiramate in chronic epilepsy.

Epilepsia 2000;41:1592-6.

70. Atefy R., Tettenborn B. Age as predictive factor for weight gain under valproic acid therapy. Epilepsia 2004;45(Suppl.):132- 3 .

71. Hiba A., Buchsbaum R., Pierro J. et al. Comparative Effectiveness of 10 Antiepileptic Drugs in Older Adults With Epilepsy. Arch Neurol 2010;67:408- 15

72. Deleu D., Al-Hail H., Mesraoua B. et al Short-term efficacy and safety of valproate sustained-release formulation in newly diagnosed partial epilepsy VIPe-study. A multicenter observational open-label study. Saudi Med J 2007;28(9):1402-7.

73. Hu Y., Huang Y., Quan F. et al. Comparison of the retention rates between carbamazepine and valproate as an initial monotherapy in Chinese patients with partial seizures: A ten-year follow-up, observational study. Seizure 2011;20(3):208-13. 74. Richens A., Davidson D.L., Cartlidge N.E. et al. A multicentre comparative trial of sodium valproate and carbamazepine in adult onset epilepsy. Adult EPITEG Collaborative Group. J Neurol Neurosurg Psychiatry 1994;57:682-7. 75. Wheless J.W., Neto W., Wang S. Topiramate, Carbamazepine, and Valproate Monotherapy: Double-Blind Comparison in Children With Newly Diagnosed Epilepsy. J Child Neurol 2004;19:135-41

76. Hunt S., Russell A., Smithson W.H. et al. Topiramate in pregnancy: Preliminary experience from the UK Epilepsy and Pregnancy Register. Neurology 2008;71:272-6.

77. Holmes L.B., Baldwin E.J., Smith C.R et al. Wyszynski Increased frequency of isolated cleft palate in infants exposed to lamotrigine during pregnancy. Neurology 2008;70:2152-8 78. Белоусова Е.Д., Ермаков А.Ю. Российское наблюдательное исследование краткосрочной эффективности и переносимости пролонгированного вальпроата натрия (Депакин Хроносфера ${ }^{\circledR}$ как препарата первой линии в лечении эпилепсии. Неврол нейропсихиатр психосом 2009;3-4;1-8.

79. Белоусова Е.Д., Ермаков А.Ю. Применение Депакин Хроносфера в качестве первой монотерапии для лечения эпилепсии у детей. Неврол нейропсихиатр психосом 2010;3:52-7. 